\title{
Исследование радиационной стойкости фотодиодов на структурах кремний-на-сапфире
}

\author{
(C) Ю.А. Кабальнов ${ }^{1}$, А.Н. Труфанов ${ }^{1}$, С.В. Оболенский ${ }^{2, \uparrow}$ \\ ${ }^{1}$ Научно-исследовательский институт измерительных систем им. Ю.Е. Седакова, \\ 603950 Нижний Новгород, Россия \\ ${ }^{2}$ Национальный исследовательский Нижегородский государственный университет им. Н.И. Лобачевского, \\ 603950 Нижний Новгород, Россия \\ E-mail: obolensk@rf.unn.ru
}

(Получена 10 января 2018 г. Принята к печати 13 сентября 2018 г.)

Теоретически и экспериментально изучены электрофизические свойства фотодиодов на основе структур кремний-на-сапфире. Показано, что по основным параметрам они не уступают кремниевым диодам, а уровень радиационной стойкости на порядок выше, чем у аналогичных диодов на объемном кремнии.

DOI: 10.21883/FTP.2019.03.47292.8813

\section{1. Введение}

Важным недостатком классических фотодиодов [1-4] на основе обратно смещенных $p-n$-переходов и барьеров Шоттки является низкий уровень их радиационной стойкости [5,6]. Дело в том, что при воздействии на полупроводниковые структуры фотодиодов импульсами $\gamma$ - и $\gamma$-нейтронного излучения ускорителей и ядерных реакторов с энергиями $0.01-10$ МэВ формируется большое количество радиационных дефектов, являющихся эффективными рекомбинационными центрами. При воздействии нейтронов формируются целые кластеры радиационных дефектов с характерным размером 30-100 нм. Такие кластеры характеризуются особенным потенциальным рельефом - они являются препятствием для основных носителей и потенциальной ямой для неосновных носителей заряда [6]. Из-за наличия таких крупных ловушек скорость рекомбинации значительно увеличивается. При уровнях воздействия, когда другие диоды и транзисторы еще могут функционировать [6,7], для многих типов фотодиодов уже наблюдается полный отказ [6], что затрудняет проектирование радиационностойких волоконно-оптических систем передачи и преобразования сигналов.

Важно, что указанные процессы увеличения скорости рекомбинации носителей заряда и снижения фоточувствительности фотодиодов практически не зависят от типа полупроводникового материала, профилей легирования, площади $p-n$-переходов, применяемых в диодах, и других конструктивных особенностей стандартных диодов [6]. В силу большой проникающей способности нейтронного излучения (до $10 \mathrm{~cm}$ и более) фотодетекторы невозможно защитить какими-либо корпусами и(или) экранами с приемлемыми массагабаритными характеристиками. В связи с этим весьма актуальным становится разработка таких конструкций диодов, в которых путем использования дополнительных слоев полупроводниковой структуры в активной области удастся увеличить их радиационную стойкость.
Для решения указанной проблемы в данной работе предложено использовать структуры кремний-насапфире (КНС), применяемые для изготовления радиационно стойких полевых транзисторов, а также интегральных схем на их основе. Так, в [8] предложено использовать такие структуры для интегральных схем фотодиодов с целью снижения чувствительности КНС структур и транзисторов к процессу ионизации материала за счет снижения объема областей кремния, из которых контактами собираются генерированные излучением электроны и дырки. Это решение известно и часто применяется для снижения вероятности сбоев и отказов интегральных схем, например, космического применения.

В отличие от [8] в данной работе представлены результаты разработки радиационно стойких дискретных фотодиодов на КНС структурах, которые выдерживают значительно больший уровень нейтронного облучения. Для этого сопоставлялись параметры фотодиодов, изготовленных на КНС структурах, и фотодиодов, изготовленных с применением аналогичной технологии, на обычных кремниевых пластинах. Поскольку концентрация ростовых дефектов в слоях кремния, эпитаксиально выращенного на сапфире, значительно выше, чем в кремниевых пластинах, важно было сопоставить параметры фотодиодов до радиационного воздействия с тем, чтобы затем корректно сравнивать радиационную стойкость фотодиодов классической конструкции и диодов на КНС структурах.

Важно, что в структурах кремний-на-сапфире при их $\gamma$-нейтронном облучении кроме указанного выше эффекта формирования центров захвата и рекомбинации в слое сапфира на границе с кремнием и в пассивирующем слое $\mathrm{SiO}_{2}$ формируется связанный положительный заряд, что ведет к возникновению потенциальной ямы для электронов в прилегающем к диэлектрику слое кремния [1,2]. Дырки, напротив, вытесняются из этих кремниевых слоев. Последнее обстоятельство приводит к существенному разделению потоков электронов и ды- 
рок в облученных фотодиодах в момент детектирования оптического излучения. Поэтому при постановке работы мы предположили, что фоточувствительность облученных диодов будет изменяться незначительно, несмотря на то что скорость рекомбинации через сформированные радиацией центры захвата носителей заряда после облучения увеличивается значительно. Ранее подобный эффект изменения фоточувствительности структур при пространственном разделении потоков носителей заряда после $\gamma$-нейтронного облучения подробно не изучался. Необходимо было определить величину положительного эффекта и возможности его применения на практике для создания конкретных диодов с повышенной радиационной стойкостью.

Экспериментальное исследование особенностей функционирования фотодиодов непосредственно в момент воздействия импульса $\gamma$ - и(или) $\gamma$-нейтронного излучения важно с точки зрения контроля времени потери работоспособности диодов, так как на фоне сильной ионизации кремния радиационным излучением чувствительность к оптическому излучению будет частично или полностью подавлена. После окончания импульса радиационного воздействия фотодиод должен восстановить свою работоспособность за приемлемое время (микросекунды). Также в ходе работы исследовалась возможность использования специальных двухэлементных фотодиодов для реализации специальной радиотехнической схемы компаратора, позволяющей детектировать полезный оптический сигнал на фоне ложного сигнала, возникающего из-за ионизирующего воздействия радиации.

Для теоретического исследования указанных процессов удобно было использовать физико-топологическое моделирование [3-5], позволяющее провести подробный анализ физических процессов транспорта носителей заряда до, в момент и после радиационного воздействия с учетом распределения потоков носителей заряда по толщине полупроводниковой структуры. Результаты расчетов сопоставлялись с экспериментальными данными.

\section{2. Конструкция и технология изготовления образцов}

Фотодиоды разрабатывались как преобразователи постоянного и импульсно-периодического оптического излучения с длиной волны 0.63 мкм в электрический сигнал. Представлены результаты разработки двух типов фотодиодов: одноэлементных, содержащих один фоточувствительный элемент (ФЧЭ), и двухэлементных, содержащих два идентичных ФЧЭ на одном кристалле с межэлементным зазором 60 мкм. Конструктивно области анода и катода фотодиодов выполнялись в виде встречно-штыревой структуры с размером фоточувствительной области $1.4 \times 1.4$ мм для одноэлементных диодов и $0.4 \times 1.4$ мм для каждого элемента двухэлементных диодов. Сопоставление двух- и одноэлементных

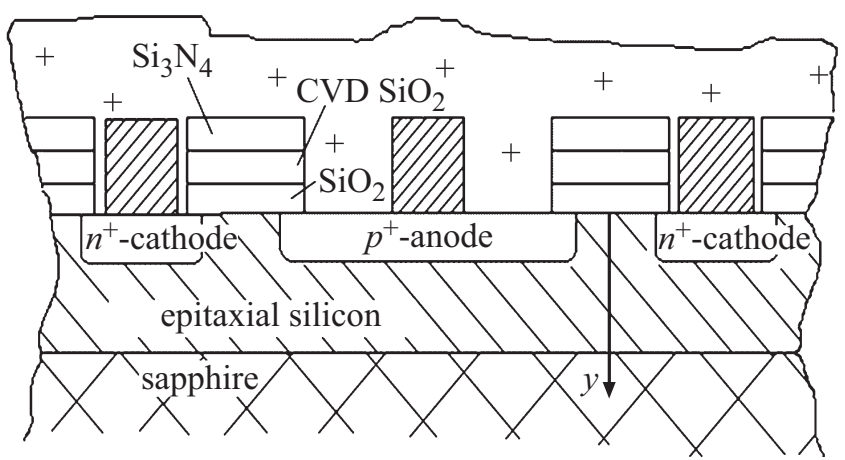

Рис. 1. Разрез структуры элементарного фотодиода.

диодов позволяло исследовать возможности детектирования оптического сигнала в условиях воздействия радиации.

Фоточувствительную область с целью увеличения токовой чувствительности формировали из 20 параллельно соединенных элементарных фотодиодов малой площади. Аноды и катоды фотодиодов были выведены к контактным площадкам, которые расположены противоположно друг к другу и симметрично относительно центра ФЧЭ. Границы отдельных областей ФЧЭ формировались травлением канавок по периметру на всю глубину эпитаксиального слоя кремния.

В качестве материала подложки использовались гетероэпитаксиальные структуры кремний-на-сапфире с толщиной нанесенного на сапфир слоя кремния 5 мкм, проводимостью $n$-типа с удельным сопротивлением от 4.5 до 10 Ом $\cdot$ см и концентрацией основной примеси не менее $10^{15} \mathrm{~cm}^{-3}$. Схематически на рис. 1 приведена структура элементарного фотодиода в разрезе. Показаны активная область $p-n$-перехода, сформированная слоем $p^{+}$-анода в слое кремния, металлизированные контакты к $p^{+}$-аноду и к $n^{+}$-катоду, межслойный диэлектрик из слоев нитрида кремния $\left(\mathrm{Si}_{3} \mathrm{~N}_{4}\right)$ и двуокиси кремния $\left(\mathrm{CVD} \mathrm{SiO}_{2}\right)$; пассивирующая пленка фосфоросиликатного стекла. Расстояние между катодом и анодом составляло 20-50 мкм, что на порядок больше толщины кремниевого слоя в структурах кремний-на-сапфире.

Данная структура была реализована по технологическому маршруту с использованием операций осаждения диэлектрических и проводящих слоев, ионного легирования, термических обработок, фотолитографий и химического травления. Для получения низких значений темнового тока фотодиодов ( 1 мкА) и достаточно высоких значений токовой чувствительности (не менее $0.3 \mathrm{~A} / \mathrm{B}$ ) по результатам моделирования выбиралось оптимальное соотношение параметров ионной имплантации и высокотемпературного отжига. Структуры фотодиодов отбраковывались по двум основным параметрам: темновому току и токовой чувствительности.

Параллельно с фотодиодами на КНС структурах проводилось изготовление по аналогичной технологии фо- 
Таблица 1. Результаты измерений параметров фотодиодов (на пластинах) в зависимости от типа и удельного сопротивления подложки

\begin{tabular}{c|c|c|c|c|c}
\hline $\begin{array}{c}\text { Тип } \\
\text { пластины }\end{array}$ & $\begin{array}{c}\text { Удельное } \\
\text { сопротивление, } \\
\text { Ом ·см }\end{array}$ & $\begin{array}{c}\text { Темновой } \\
\text { ток, мкА } \\
\text { (при 15 В) }\end{array}$ & $\begin{array}{c}\text { Мощность } \\
\text { излучателя, } \\
\text { мВт }\end{array}$ & $\begin{array}{c}\text { Величина } \\
\text { фототока, } \\
\text { мкА }\end{array}$ & $\begin{array}{c}\text { Токовая } \\
\text { чувствительность, } \\
\text { А/Вт }\end{array}$ \\
\hline Кремний & 4.5 & 0.01 & 2.1 & 102 & 0.7 \\
Кремний & 4.5 & 0.01 & 4.6 & 200 & 0.63 \\
КНС & 6.9 & 1.5 & 2.1 & 64 & 0.44 \\
КНС & 9.02 & 0.76 & 2.1 & 36 & 0.25 \\
КНС & 6.3 & 1.46 & 2.1 & 68 & 0.47
\end{tabular}

тодиодов на объемном кремнии. Исследуемые структуры фотодиодов были промаркированы следующим образом:

- ФД1-КНС - фотодиоды с одним фоточувствительным элементом, изготовленные на структурах КНС;

- ФД1-Si - фотодиоды с одним ФЧЭ, изготовленные на подложках из объемного кремния;

- ФД2-КНС - фотодиоды с двумя ФЧЭ, изготовленные на структурах КНС,

- ФД2-Si - фотодиоды с двумя ФЧЭ, изготовленные на подложках из объемного кремния.

\section{3. Параметры диодов до облучения}

Параметры фотодиодов измерялись при двух режимах работы: фотогальваническом и фотодиодном, при непрерывном и импульсно-периодическом [3,4] режимах работы источника оптического излучения. В табл. 1 представлены результаты измерений темнового тока и токовой чувствительности фотодиодов в зависимости от типа и параметров подложек.

Фотодиоды, созданные по кремниевой технологии, имеют характеристики лучше, что обусловлено более совершенной структурой монокристаллического кремния. Гетероэпитаксиальные структуры кремний-насапфире имеют повышенную дефектность, связанную с влиянием внутренних механических напряжений на границе кремний-сапфир. В табл. 2 сопоставлены ве-

Таблица 2. Средние значения темнового тока и токовой чувствительности для различных типов фотодиодов после их корпусирования

\begin{tabular}{l|c|c|c}
\hline $\begin{array}{c}\text { Тип } \\
\text { фотодиода }\end{array}$ & $\begin{array}{c}\text { Темновой } \\
\text { ток, мкА } \\
\text { (при 15 В) }\end{array}$ & $\begin{array}{c}\text { Величина } \\
\text { фототока, } \\
\text { мкА }\end{array}$ & $\begin{array}{c}\text { Токовая } \\
\text { чувствительность, } \\
\text { А/Вт }\end{array}$ \\
\hline ФД1-Si & 0.02 & 90.2 & 0.622 \\
Ф1-КНС & 0.81 & 59.2 & 0.408 \\
ФД2-Si & 0.02 & 32.45 & 0.78 \\
ФД2-КНС & 0.36 & 19.95 & 0.48
\end{tabular}

Примечание. При измерениях использовался излучатель мощностью $2.1 \mathrm{мB}$. личины темнового тока и токовой чувствительности четырех типов фотодиодов после их корпусирования.

В фотодиодном режиме при изменении обратного напряжения от 1 до $5 \mathrm{~B}$ значения темнового тока фотодиодов ФД1-КНС и ФД2-КНС увеличивались на $\sim 25 \%$, а средние значения токовой чувствительности возрастали на 7.5\%. Измеренные значения коэффициента фотоэлектрической связи между двумя ФЧЭ фотодиодов ФД2-КНС не превышали 2.5\%. Таким образом, экспериментально было показано, что полезный сигнал может быть принят только одним ФЧЭ, что важно для реализации радиотехнической схемы сравнения, позволяющей отделить полезный сигнал от ложного, возникающего при ионизирующем воздействии радиации одновременно на оба ФЧЭ. Благодаря тому, что ФЧЭ расположены на кристалле близко друг к другу, параметры радиационного воздействия на такие диоды будут максимально схожими, а значит, и ложные сигналы, генерируемые ФЧЭ, будут подобны. Это позволит отличить ложный сигнал от полезного с помощью простейшей радиотехнической схемы сравнения.

Пороговая мощность, определенная в соответствии с методикой [4] по уровню фототока, соответствующего удвоенному значению темнового тока, составляла 2.0 мкВт для ФД1-КНС и 1.0 мкВт для ФД2-КНС. Соответственно по уровню 30-процентного превышения темнового тока для ФД1-КНС пороговая мощность составляла 0.7 мкВт, а для ФД2-КНС 0.3 мкВт.

Представленные выше результаты были получены при измерениях в нормальных условиях при комнатной температуре. Измеренные значения параметров фотодиодов в диапазоне температур от -50 до $+85^{\circ} \mathrm{C}$ приведены в табл. 3. Как видно из представленных данных, величина темнового тока с ростом температуры достаточно интенсивно возрастает, а величина токовой чувствительности при отрицательных температурах снижается на 15-30\%. Причины этого обсуждаются в следующем разделе.

Исследования импульсно-периодических параметров фотодиодов проводились как в фотогальваническом, так и в фотодиодном режимах при воздействии модулированным излучением от лазерного модуля. Параметры 
Таблица 3. Средние значения параметров фотодиодов в диапазоне температур от -50 до $+85^{\circ} \mathrm{C}$

\begin{tabular}{c|c|c|c|c}
\hline $\begin{array}{c}\text { Тип } \\
\text { фотодиода }\end{array}$ & $\begin{array}{c}\text { Температура, } \\
{ }^{\circ} \mathrm{C}\end{array}$ & $\begin{array}{c}\text { Темновой } \\
\text { ток, мкА } \\
\text { (при 5 В) }\end{array}$ & $\begin{array}{c}\text { Величина } \\
\text { фототока, } \\
\text { мкА }\end{array}$ & $\begin{array}{c}\text { Токовая } \\
\text { чувствительность, } \\
\text { А/Вт }\end{array}$ \\
\hline \multirow{3}{*}{ Фд1-КНС } & -50 & 0.11 & 157 & 0.32 \\
& 23 & 0.94 & 213 & 0.434 \\
& 60 & 7.7 & 225 & 0.459 \\
\multirow{2}{*}{ ФД2-КНС } & 85 & 30.9 & 61.5 & 0.477 \\
& -50 & 0.11 & 73.6 & 0.526 \\
& 23 & 0.24 & 78.9 & 0.564 \\
\end{tabular}

фотодиодов определялись методом сравнительного анализа полученных осциллограмм и эталонного сигнала непосредственно от генератора сигналов. Собственная постоянная времени фотодиодов определялась как разность по времени поданного на излучающий диод и принятого на фотодиоде сигналов. По результатам измерений величина собственной постоянной времени для всех типов фотодиодов не превышала 100 нс.

\section{4. Математическая модель}

Для моделирования процессов транспорта электронов в структурах фотодиодов использовалась физикотопологическая модель в квазигидродинамическом приближении. Решались уравнения Пуассона, непрерывности, а также учитывались выражения для плотности тока электронов и дырок [6,7]:

$$
\begin{gathered}
\Delta V=\frac{q}{\varepsilon}\left[n\left(F_{N}\right)+p\left(F_{N}\right)-N_{+}\left(F_{N}\right)+N_{-}\left(F_{N}\right)\right], \\
\mathbf{j}_{i}=\mathbf{j}_{n}+\mathbf{j}_{p}+\varepsilon \frac{\partial \mathbf{E}}{\partial t}, \quad \mathbf{E}=-\nabla V, \\
\frac{\partial n\left(F_{N}\right)}{\partial t}=\frac{1}{q}\left(\nabla, \mathbf{j}_{n}\right)+G-R, \\
\mathbf{j}_{n}=-q n \mathbf{v}_{n}\left(F_{N}\right)+q \nabla\left[D_{n}\left(F_{N}\right) n\left(F_{N}\right)\right], \\
\frac{\partial p\left(F_{N}\right)}{\partial t}=\frac{1}{q}\left(\nabla, \mathbf{j}_{p}\right)+G-R, \\
\mathbf{j}_{p}=-q p \mathbf{v}_{p}\left(F_{N}\right)+q \nabla\left[D_{p}\left(F_{N}\right) p\left(F_{N}\right)\right],
\end{gathered}
$$

где $V$ - потенциал, $n-$ концентрация электронов, $p$ - концентрация дырок, $N_{+}, N_{-}-$концентрации положительно и отрицательно заряженных ионов (доноров, акцепторов, радиационных дефектов), $\mathbf{j}_{n}, \mathbf{j}_{p}, \mathbf{j}_{t}-$ плотности электронного, дырочного и полного токов, $D_{n}, D_{p}$ - коэффициенты диффузии электронов и дырок, $\mathbf{v}_{n}, \mathbf{v}_{p}$ - дрейфовые скорости электронов и дырок, $\mathbf{E}-$ напряженность электрического поля, $\varepsilon$ диэлектрическая проницаемость, $F_{N}-$ флюенс нейтронов, $q$ - абсолютная величина заряда электрона,
$G$ - коэффициент генерации носителей заряда при воздействии излучения, $R-$ коэффициент рекомбинации, $t-$ время. Для учета изменения параметров модели после нейтронного облучения вводились их зависимости от флюенса облучения [7]. Для учета воздействия дозы $\gamma$-излучения пропорционально уровню облучения (но с иной скоростью) изменялись те же параметры модели, что и при учете нейтронного облучения [7].

Применялись граничные условия смешанного типа: на свободных поверхностях занулялись градиенты концентрации электронов и дырок, а также градиенты потенциала и энергии. На контактах задавались значения концентрации электронов и дырок, соответствующие уровням легирования полупроводника, энергия электронов считалась равной тепловой, а потенциал устанавливался согласно экспериментальным значениям.

Для калибровки модели проводился расчет параметров фотодиодов, соответствующих представленным в табл. 1-3 данным. Расчеты показали, что погрешность модели составляет $10-30 \%$. Затем проводился расчет радиационного воздействия на диоды.

Для аппроксимации изменения концентрации носителей заряда в полупроводниковом материале после облучения нейтронами использовалась формула [6]

$$
n_{F}=n_{0} \exp \left(-\frac{n_{0}^{a} F_{n}}{n_{0} k}\right),
$$

где для $n$-Si и $p$-Si $a=0.23$, для $n-\mathrm{Si} k=387$, для $p$-Si $k=444$.

При введении уровней радиационных дефектов в запрещенную зону увеличивается вероятность непрямой рекомбинации, описывающаяся через коэффициент изменения времени жизни [6]:

$$
\Delta\left(1 / \tau_{r}\right)=1 / \tau_{r f}-1 / \tau_{r}=K_{\tau} F_{n},
$$

где $\tau_{r}, \tau_{r f}$ - времена жизни носителей до и после облучения соответственно. 

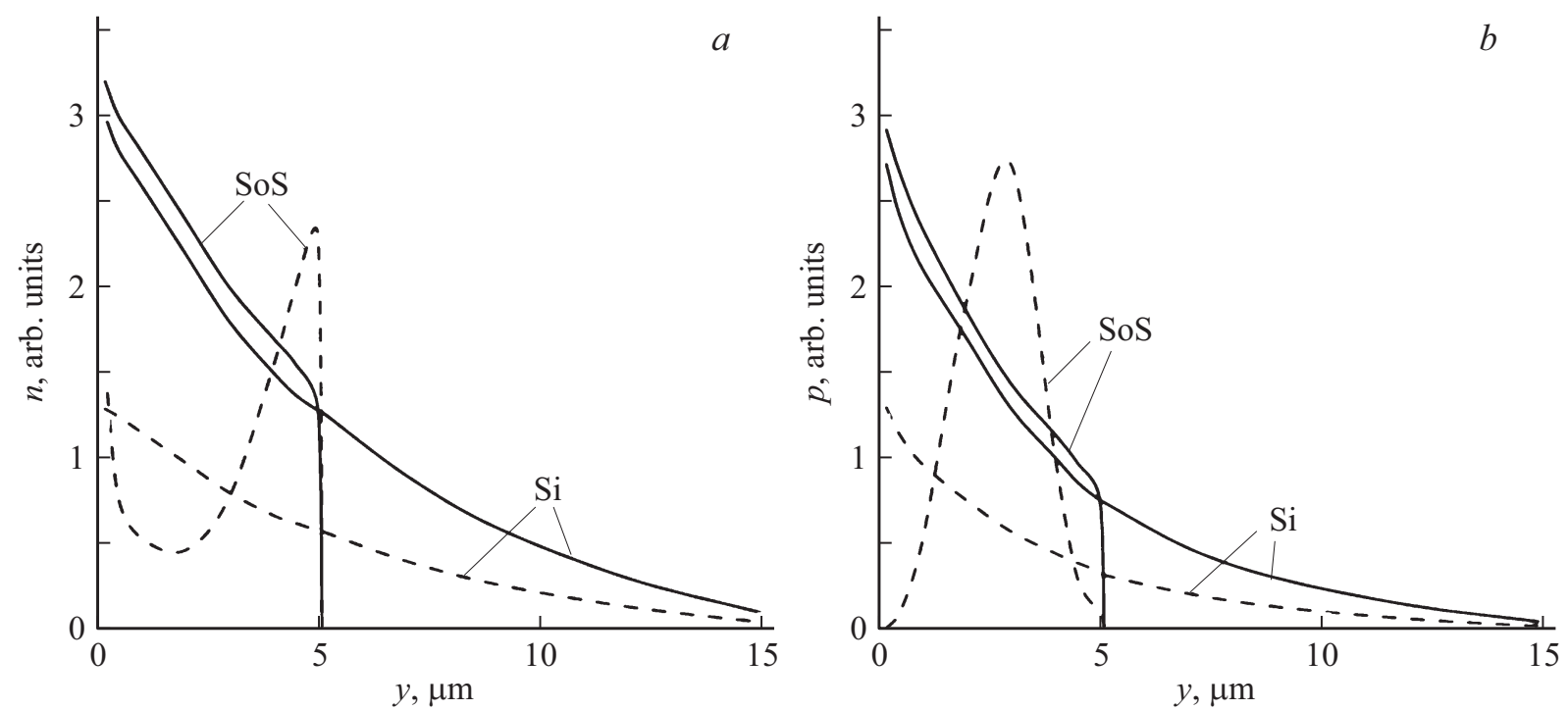

Рис. 2. Стационарные распределения электронов $(a)$ и дырок $(b)$, генерированных непрерывным оптическим излучением и создающих электрический ток в КНC (SoS) структурах и структурах на кремнии ( $\mathrm{Si}$ ) до (сплошная линия) и после $\gamma$-нейтронного облучения (штриховая линия). Видно накопление электронов вблизи границы кремний-сапфир и кремний-SiO 2 после радиационного облучения из-за возникновения положительных связанных зарядов на границе с сапфиром. Снижение концентрации носителей заряда после облучения связано с рекомбинацией на радиационных дефектах.

После облучения нейтронами выражения для $K_{\tau}$ имеют вид [6]

$$
\begin{gathered}
K_{\tau m}=\frac{2.1+0.18 \rho_{n 0}+9.0 \cdot 10^{-5} \rho_{n 0}^{2}}{1+1.4 \cdot 10^{-2} \rho_{n 0}} \quad(n-\mathrm{Si}), \\
K_{\tau p}=\frac{1.4+8.6 \cdot 10^{-2} \rho_{p 0}+1.2 \rho_{p 0}^{2}}{1+3.8 \cdot 10^{-2} \rho_{p 0}} \quad(p-\mathrm{Si}),
\end{gathered}
$$

где $\rho_{n 0}$ и $\rho_{p 0}$ выражаются в см${ }^{-3}$.

Изменение указанных выше электрофизических параметров кремния после $\gamma$-облучения слабее, чем после нейтронного, тем не менее оно учитывалось аналогично нейтронному воздействию на основе данных [6]. Генерированный $\gamma$-излучением связанный заряд на границе сапфир-кремний и кремний- $\mathrm{SiO}_{2}$ вводился в ячейки расчетной сетки модели на основе данных [6].

Для учета изменения концентрации носителей заряда в момент облучения в уравнения вводилось слагаемое, ответственное за генерацию неравновесных носителей $[6,7]$,

$$
G=g_{0} P_{\gamma}, \quad g_{0}=6.25 \cdot 10^{15} \rho / W_{i}\left(\text { пар/см}{ }^{3} \cdot \Gamma \mathrm{p}\right),
$$

где $P_{\gamma}$ - мощность поглощенной дозы излучения $(\Gamma \mathrm{p} / \mathrm{c})$, $\rho$ - плотность материала $\left(\Gamma / \mathrm{cm}^{3}\right), W_{i}-$ средняя энергия ионизации $\left(2.6\right.$ эВ), $g_{0}=4.4 \cdot 10^{15} \mathrm{~cm}^{-3} \cdot \Gamma p^{-1}[6]$. Рекомбинация носителей заряда учитывалась по стандартной формуле Шокли-Рида-Холла [6].

Учет температуры в модели проводился стандартным образом - приведенные выше электрофизические параметры модели изменялись пропорционально с изменением температуры согласно экспериментальным данным [6].

\section{5. Моделирование радиационной стойкости диодов}

Расчет распределения концентрации генерированных оптическим излучением электронов и дырок показал, что ионизация происходит в слое кремния толщиной $\sim 4$ мкм. В ходе их движения в $p-n$-переходе под действием электрического поля и диффузии они заполняют всю толщу слоя КНС структур (5 мкм), а в обычных кремниевых структурах диффундируют в глубину до 10-20 мкм, что сопоставимо с расстоянием между анодом и катодом диода.

Результаты расчетов распределения потенциала, плотности тока, концентрации электронов и дырок до и после различных видов радиационного воздействия показали, что границы раздела кремний-сапфир и кремний- $\mathrm{SiO}_{2}$ оказывают значительное влияние на характеристики приборов. Так, наличие сапфира приводит к ограничению потоков носителей заряда в глубину структуры в отличие от диодов, изготовленных на кремниевых пластинах (рис. 2). Благодаря тому, что длина траектории движения электронов и дырок в КНС структурах меньше, чем в структурах на кремнии, вероятность захвата неосновного носителя заряда на радиационный дефект вдоль траектории движения для КНС структур ниже в 2-3 раза. Поэтому параметры КНС фотодиодов (см. табл. 1-3) сопоставимы с параметрами диодов на объемном кремнии, хотя и незначительно им уступают.

Радиационно-стимулированное накопление положительного заряда вдоль границы с кремнием в слоях сапфира и оксида кремния способствует формированию 
потенциальной ямы для электронов и потенциального барьера для дырок (см. рис. 2 и 3). Указанные области диэлектриков и прилегающих к ним слоев кремния содержат относительно небольшое количество радиационных дефектов, так как кластеры дефектов имеют объемную форму и распределены во всем слое кремния и сапфира. Поэтому скорость захвата носителей заряда радиационными дефектами при их движении вдоль границ раздела кремний-диэлектрик несколько ниже, чем для случая кремниевых структур. Кроме того пространственное разделение потоков носителей зарядов (рис. 3) в КНС структурах после облучения - электронов вдоль границы с сапфиром и оксидом кремния, а дырок в центральной части кремниевого слоя - снижает вероятность электронно-дырочной рекомбинации, в том числе при захвате одного из носителей радиационным дефектом.

В итоге как точечные радиационные дефекты, так и их кластеры гораздо слабее влияют на рекомбинацию носителей заряда в структурах кремний-на-сапфире, чем в кремниевых пластинах.

Результаты моделирования показали, что экспериментально зарегистрированное отличие параметров фотодиодов при различных температурах связано с изменением тока утечки обратно смещенного $p-n$-перехода, а приращение тока диодов из-за воздействия как оптического, так и радиационного излучений слабо зависит от температуры в исследуемом диапазоне.

Моделирование процесса функционирования диодов с двумя чувствительными элементами проводилось по следующей схеме. Предполагалось, что оптическое излучение сфокусировано только на одном из фоточувствительных элементов, а радиационное излучение воздействует на оба элемента. В случае такого режима

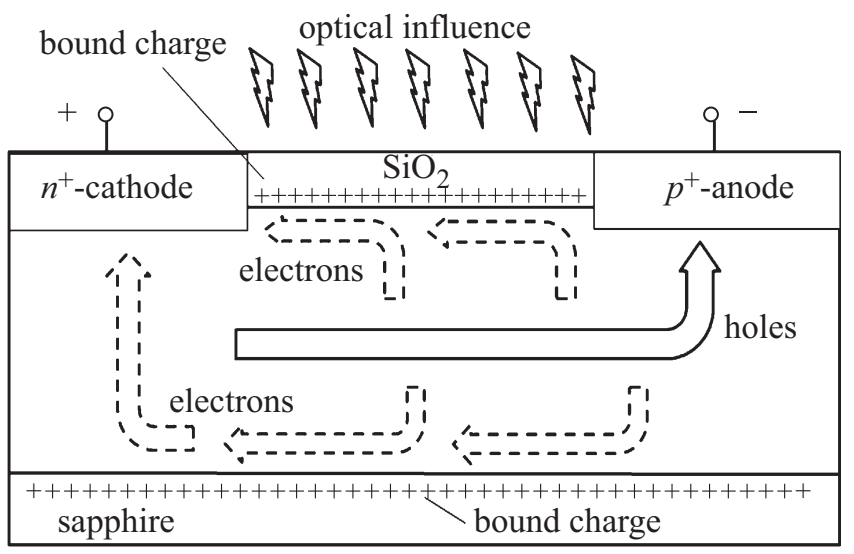

Рис. 3. Схема пространственного разделения потоков электронов и дырок после $\gamma$-нейтронного облучения в КНС структурах из-за возникновения связанных положительных зарядов в слоях $\mathrm{SiO}_{2}$ и сапфира на границе с кремнием. Большая часть оптического излучения поглощается в слое кремния, а $\gamma$-нейтронное излучение пронизывает структуру насквозь, так что лишь небольшая часть поглощается активной областью диода. работы простейшая схема компаратора, подключенная к выходам различных фоточувствительных элементов одного фотодиода, легко будет отличать ложный сигнал, возникающий из-за ионизирующего воздействия радиации, от полезного оптического сигнала.

В ходе проведенного моделирования исследовалась возможность применения минимальных средств фокусировки, т.е. предполагалось, что торец оптического волокна, через которое подается полезный оптический сигнал на фотодиод, расположен над одним из фотодиодов, а другой фотодиод засвечивается значительно меньше. Расчеты показали, что как до, так и после радиационного облучения описанная выше простейшая конструкция позволяет отличить полезный сигнал от ложного.

Кроме того, экспериментальные данные показали, что различие в параметрах соседних фоточувствительных элементов значительно меньше, чем фотоэлементов различных диодов, как до, так и после воздействия радиации. В этом случае результаты моделирования процесса детектирования оптического сигнала в момент радиационного облучения позволяют утверждать, что использование предложенной в статье двухэлементной конструкции фотодиодов дает возможность реализовать радиотехническую схему детектирования полезного сигнала на фоне ложного в диапазоне мощностей доз $\gamma$-излучения вплоть до $10^{11} \mathrm{P} / \mathrm{c}$. Использование двух отдельных фотодиодов для реализации той же цели неудобно, так как связано с необходимостью подбора близких по параметрам диодов с точки зрения их радиационной чувствительности.

\section{6. Экспериментальное исследование радиационной стойкости диодов}

С использованием комплекса моделирующих установок и имитационного оборудования [5] были проведены исследования стойкости образцов к воздействию ионизирующего излучения. Исследовалось воздействие статического $\gamma$ - и $\gamma$-нейтронного излучения, а также импульсного $\gamma$-излучения, генерированных ядерным реактором, непрерывным и импульсным генераторами $\gamma$-квантов соответственно.

Измерения параметров фотодиодов до и после статического облучения проводились в двух режимах: измерялась величина фотоэдс диодов без подачи внешнего смещения; измерялась фоточувствительность диодов путем сопоставления темнового тока и фототока при подаче обратного смещения. Результаты измерений приведены в табл. 4.

В момент импульсного $\gamma$-облучения проводилось измерение наведенного радиацией тока $\left(I / I_{0}\right)$ и контролировалось время потери работоспособности диодов. Также проводился расчет параметров диодов в момент и после облучения. Результаты расчетов и измерений представлены на рис. 4. 
Таблица 4. Сравнение радиационной стойкости кремниевых и КНС фотодиодов после $\gamma$-нейтронного облучения (средняя энергия $1 \mathrm{MэB)} \mathrm{с} \mathrm{флюенсом} \mathrm{нейтронов} 10^{13} \mathrm{~cm}^{-2}$ и дозой $\gamma$-квантов $10^{5}$ рад

\begin{tabular}{l|c|c|c|c}
\hline \multirow{2}{*}{} & \multicolumn{2}{|c|}{ Уменьшение уровня фотоэдс, \% } & \multicolumn{2}{c}{ Уменьшение уровня фоточувствительности, \% } \\
\cline { 2 - 5 } & Объемный кремний & Кремний-на-сапфире & Объемный кремний & Кремний-на-сапфире \\
\hline$\gamma$-облучение & $<1(0.76)$ & $<1^{*}(0.34)$ & $60-90(80)$ & $<1(0.1)$ \\
\hline$\gamma$-нейтронное облучение & $10-15(13)$ & $5-7(3.2)$ & $70-90(87)$ & $1-5(0.6)$
\end{tabular}

Примечание. В скобках приведены результаты расчетов. Величина изменений параметров указана в процентах от исходного значения до облучения. *B некоторых образцах наблюдалось повышение на $15-25 \%$ уровня фотоэдс после $\gamma$-облучения, по-видимому, за счет радиационно-стимулированного отжига технологических дефектов.

Расчеты и эксперименты показали, что дефектообразующее воздействие статического $\gamma$-облучения незначительно влияет на характеристики фотодиодов. Деградация параметров диодов на структурах КНС после нейтронного облучения выражалась в единицах процентов, при этом аналогичная деградация фотодиодов на кремнии составляла $>80 \%$, т. е. фактически диоды теряли свою работоспособность. На всех типах фотодиодов наблюдался рост темнового тока в процессе статического радиационного воздействия, но его уровень не выходил за пределы 1.5 мкА.

При воздействии импульсного $\gamma$-излучения (длительность импульса $\sim 30$ нс) время потери работоспособности образца, изготовленного на кремнии, составляло 150 мкс (рис. 4), а для образцов ФД1,2-КНС было $\sim 1$ мкс. Такое сильное различие обусловлено значительно меньшим количеством генерированных электронов в слое кремния КНС структур по сравнению с диодами на объемном кремнии, где во время воздействия $\gamma$-излучения ионизуется вся кремниевая подложка, из которой затем электроны и дырки вытягиваются электрическим полем в анод и катод диода.

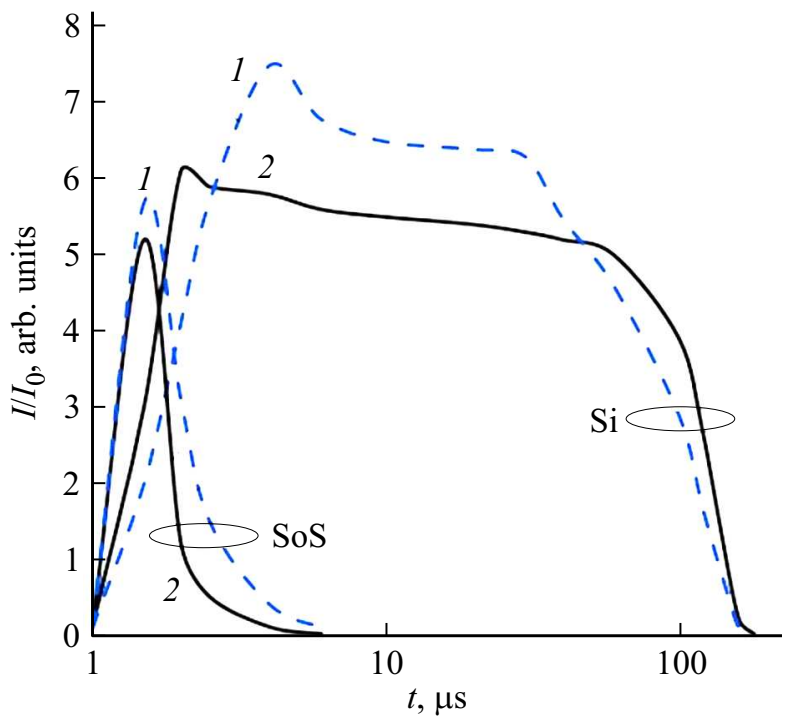

Рис. 4. Осциллограмма сигнала с выхода фотодиодов ФД1-Si $(\mathrm{Si})$ и ФД1-КНС $(\mathrm{SoS})$ при воздействии импульса $\gamma$-излучения с мощностью дозы $10^{12} \mathrm{paд} / \mathrm{c} .1$ - теория, 2 - эксперимент.

\section{7. Заключение}

Результаты расчетов и экспериментов показывают, что фотодиоды на основе КНС структур обладают электрическими характеристиками, сопоставимыми с характеристиками кремниевых диодов, а уровень их радиационной стойкости существенно превосходит аналогичный уровень для кремниевых диодов. Указанные преимущества достигаются за счет особенностей транспорта электронов и дырок в КНС структурах, когда из-за влияния границы раздела кремний-сапфир в КНС структурах происходит разделение потоков носителей заряда, так что их рекомбинация на кластерах радиационных дефектов в существенной степени подавлена.

Предложенное в данной работе решение [9], повышающее уровень радиационной стойкости диодов, может в дальнейшем использоваться для повышения стойкости фототранзисторов на КНС структурах.

\section{Список литературы}

[1] А.М. Филачев, И. И. Таубкин, М. А. Тришенков. Твердотельная фотоэлектроника. Фотодиоды (М., Физматкнига, 2011).

[2] В.М. Стучебников, В.С. Папков. Электронная промышленность. Материалы для новых направлений электронной техники, 8, 92 (1980).

[3] А.И. Астайкин, М.К. Смирнов. Основы оптоэлектроники (Саров, РФЯЦ-ВНИИЭФ, 2001).

[4] Н.Ф. Геда. Измерение параметров приборов оптоэлектроники (М., Радио и связь, 1981).

[5] В.П. Бутин, В.Ф. Зинченко, А.А. Романенко. Система радиационных испытаний изделий электронной техники (М., Радио и связь, 2004).

[6] В.С. Першенков, В.Д. Попов, А.В. Шальнов. Поверхностные радиационные эффекты в элементах интегральных микросхем (М., Энергоатомиздат, 1988).

[7] С.В. Оболенский. Изв. вузов. Электроника, 6, 3138 (2002).

[8] Л.М. Самбурский. Автореф. канд. дис. (Зеленоград, ИППМ PAH, 2013).

[9] Ю.А. Кабальнов, В.К. Киселев, А.Н. Труфанов. А.c. № 2611552 (17 июля 2015).

Редактор Л.А. Шаронова 


\section{Radiation hardness of silicon-on-sapphire} photodiodes

Yu.A. Kabalnov ${ }^{1}$, A.N. Trufanov ${ }^{1}$, S.V. Obolensky ${ }^{2}$

${ }^{1}$ Sedakov Scientific Research Institute

of Measurement Systems,

603950 Nizhny Novgorod, Russia

${ }^{2}$ Lobachevsky University of Nizhny Novgorod,

603950 Nizhny Novgorod, Russia

Abstract Electrical properties of silicon-on-sapphire photodiodes were investigated theoretically and experimentally. It has been shown, that basic parameters of photodiodes was equal to the parameters of analog silicon photodiodes, but radiation hardness by order of magnitude greater. 